\section{A fresh start needed for dental contracts in Wales}

Replacing the current dental contract targets in Wales with a new system would be of benefit to both dentists and patients, as well as boosting morale within the sector, according to the National Assembly's Health, Social Care and Sport Committee.

The NHS Dental Services Contract came into force in 2006 in Wales and pays an annual amount for dental work which is split into Units of Dental Activity (UDA).

Because the payment is the same whether a dentist undertakes one or more similar procedures, the Committee was told there was no incentive for dentists to take on high needs patients, as they would be paid the same amount for doing more work.

The Committee is concerned that the current UDA system may discourage some dentists from taking on high needs patients, particularly in areas of deprivation where poorer access to dental services already exists.

Dai Lloyd AM, Chair of the Health, Social Care and Sport Committee, said: 'What is clear to this Committee is that the current NHS contract arrangements for dentists simply aren't working.

'Paying someone the same amount to deliver a course of treatment on a patient regardless of the amount of work involved makes little sense.

'Therefore, this Committee believes it is time to end the current arrangements and find a new way of making sure everyone in Wales has access to quality dental services regardless of where they are.'

The Committee also looked at waiting times for orthodontic treatment and ways of improving these.

Progress with the Welsh Government's Designed to Smile programme was welcomed but the Committee would like to see the oral health programme extended to older children.

The Committee makes six recommendations in its report, including:

$\rightarrow$ That the Welsh Government replaces the current Unit of Dental Activity targets with a new, more appropriate and more flexible system for monitoring outcomes to include a focus on prevention and quality of treatment

$\rightarrow$ That the Welsh Government ensures and monitors the consistent reinvestment of clawback money recovered by health boards back into dentistry services until a new system for monitoring outcomes is in place and

$\rightarrow$ That the Welsh Government undertakes an evaluation to determine if the UK wide recruitment system effectively supports a strategy to increase the recruitment of those who are Welsh domiciled and the levels of retention of students generally following training.

The report will now be considered by the Welsh Government.

\subsection{3\% uplift for Northern Ireland GDPs approved}

BDA Northern Ireland has written formally to accept the Department of Health's pay uplift offer for 2018/19.

The uplift for contractor General Dental Practitioners for 2018/19 will see the DDRB recommendation of $2 \%$ net of expenses being applied, equating to an actual uplift of $2.73 \%$ backdated to 1 April 2018. According to the Department of Health, this represents a total investment of $£ 2.9$ million in regional dental services.

Chair of the BDA Northern Ireland Dental Practice Committee, Richard Graham, commented: 'We acknowledge that this year's 2.73\% uplift to fees and allowances represents the largest uplift GDPs have seen for some time. However, this is in a context of successive years of wholly inadequate uplifts of $1 \%$ pay caps, no uplifts, active cuts, and at a time when the cost of providing Health Service dentistry has increased significantly.

'A workstream has been set up to analyse the fall in Health Service income in response to a request by the $\mathrm{BDA}$. We intend to continue to engage proactively with DoH and HSCB to highlight the fall in Health service income and increase in expenses.'

\section{SPRINGERNATURE}

